\title{
Waiting in line at a fashion store: psychological and emotional responses
}

\author{
Soozin Park*, Kyeongsun Min and Yuri Lee
}

\author{
* Correspondence: sooz1005@snu.ac.k \\ Seoul National University College of \\ Human Ecology, 1 Gwanak-ro, \\ Gwanak-gu, Seoul 151-742, Korea
}

\begin{abstract}
Waiting in a service context is known to negatively affect consumer evaluation of services and service providers. However, this study investigates the positive effects of waiting — such as expected customer competition, excitement, and purchase intention-during the purchase of fashion merchandise. We classified waiting into four types based on whether waiting occurs, whether customers receiver a filler, or whether a filler is related to the context. A scenario-based online survey was conducted for empirical testing. After reading the scenario, 266 respondents replied to a questionnaire regarding expected competition, excitement, and purchase intention. The findings indicated that expected competition, excitement, and purchase intention differed significantly according to the wait type. Customers provided with a context-related filler reported the highest expected competition, excitement, and purchase intention, and excitement was found to mediate the relationship between expected competition and purchase intention. This paper ends by discussing its implications for managing waiting at a fashion store.
\end{abstract}

Keywords: Wait; Filler; Expected competition; Excitement; Purchase intention

\section{黛 Springer}

\section{Introduction}

Most people shop to change their mood or alleviate stress or boredom, even when they do not need anything specific. The hedonic utility of shopping is considered as important as its practical utility. Shopping is both a pleasant experience and considered one of life's necessities. Customers often queue up in front of stores to purchase fashion items; a long wait is not something new. For example, since 2004, many people in the United Kingdom and Korea have been camping out in front of H\&M stores each time the stores launches products in collaboration with a designer (Arthurs 2012; Kim 2012; Lee 2012). Some luxury brand department stores keep customers queuing in front of their stores to prevent congestion and provide better one-to-one service. The most active shopping seasons, for example Black Friday and Christmas in the U.S., are no exceptions: seeing long lines of customers waiting to purchase fashion items has become a global norm.

The phenomenon of waiting customers is common in the service sector, and successfully managing it is an important task (Katz et al. 1991). Research on industries such as medical services (Tansik and Routhieaux 1999; Yoon and Kim 2003), bank services (Chebat et al. 1995; Houston et al. 1998; Katz et al. 1991), dining services (Davis 
and Heineke 1998; Davis and Vollmann 1990), and airline services (Taylor 1995) focused on how to reduce the negative impact of long waits.

This study seeks to understand the waiting phenomenon and customer response during the process of purchasing a tangible product, a fashion item, which has rarely been studied in this context. This research emphasizes that the waiting experience during the purchase of a fashion product can generate a positive response, unlike the experience of waiting to receive an intangible service.

This research focuses on purchasing luxury products, which have the competence of exclusivity, well-known brand identity, high brand awareness, and perceived quality; these serve to retain sales levels and customer loyalty. As a brand's prestige fades if everyone possesses the product (Phau and Prendergast 2000), luxury brands control their brand diffusion. They also line up their customers in front of their stores to maintain brand image and provide one-to-one service. This research examines the customer response to waiting while purchasing a luxury fashion product, highlights the importance of properly managing customer waits, and suggests specific and practical methods of improving the customer wait experience.

\section{Literature review}

\section{Customer wait time}

\section{Customer wait time in the context of services versus goods}

Waiting to receive a service is broadly defined as the time from the moment customers are ready to receive a service to the moment they actually receive it (Taylor 1994; Jin et al. 2009). Depending on when the wait occurs, this period can be categorized as a pre-process wait, in-process wait, and post-process wait (Dube-Rioux et al. 1989). This study understands waiting to purchase goods as the process by which customers wait to obtain a fashion product; this delay, caused by in-store crowd control, is similar to waiting to receive a service. When the waiting types identified by Dube-Rioux et al. (1989) are applied to the context of purchasing a fashion item, waiting can be categorized into waits outside and waits inside the store. The former occur before customers explore or purchase a product and can be regarded as a pre-process wait. Waits inside the store are in-process waits that occur after customers enter the store to explore and purchase a product; these can be categorized as waits for trial and waits for payment. Waits for payment are customers' post-process wait (i.e., waiting in line) at the cash register to purchase a product. Unlike in the service context, purchasing fashion goods is strongly affected by limited supply. The psychological and emotional responses induced by customers' waits to purchase scarce goods differ from those felt when waiting to receive a service.

\section{Positive and negative customer responses to waiting}

Most research on waiting has focused on how the customer wait experience impacts service quality evaluation, customer satisfaction, and negative emotional responses. Waiting negatively affects service quality evaluation (Antonides et al. 2002; Houston et al. 1998; Cho and Kim 2007) and reduces customer satisfaction with service (Davis and Vollmann 1990; Davis and Heineke 1998; Leclerc et al. 1995). Furthermore, waiting induces negative emotions such as anger and uncertainty (Taylor 1994), which consequently mediate the relationship between service quality evaluation and customer satisfaction (Hui and Tse 1996; Houston et al. 1998). 
However, Yoo and Kim (1994) argue that customers shop with a purpose-to not only purchase products but also collect information, relieve boredom, and change their mood. Park (2000) adds that waits can lead to a positive response for customers who have a positive visiting purpose, such as when visiting restaurants, amusement parks, or theaters. Furthermore, Koo and Fishbach (2010) suggest that customers tend to evaluate a product as more valuable when people are waiting in line to buy it. Therefore, we expect that customers waiting to purchase a product, unlike those waiting to receive a service, will demonstrate positive responses to waiting. Fashion items differ from those in other product categories, as they are used to exhibit personal uniqueness and social identity. Fashion items are also subject to scarcity effects: products perceived as scarce are believed to be more valuable (Lynn 1991). Therefore, consumers are more competitive and excited about buying fashion products perceived as scarce.

Most people expect to find more reasonable prices (Parker et al. 2003) and more attractive markdowns (Shergill and Chen 2008) in outlet malls than in traditional department stores. This study focuses on waits in luxury outlet shopping malls, popular among those seeking relatively inexpensive luxury products. People often wait in long queues to enter these popular stores. During their wait, retailers can help consumers imagine their shopping experience before they enter the store. This study explores how wait times in luxury outlet shopping malls could provoke positive customer responses through the use of fillers.

\section{Filling wait time}

A filler is an object or action used to fill a wait time. Gilliland et al. (1946) explain that customers fill their wait times with mental and physical activities that divert attention from the wait itself. Taylor (1994) elaborates that waiting with friends rather than waiting alone or waiting while reading a newspaper rather than waiting while doing nothing relieves the tedium of waiting.

Fillers can be either context-related or context-unrelated depending on their relevance to the shopping context (Taylor 1994; 1995). For example, waiting restaurant customers can be provided a sample of a dish (i.e., related filler) or a television to watch (i.e., unrelated filler). Similarly, while waiting to purchase fashion goods, customers can be provided with fashion catalogs (i.e., related filler) or newspapers (i.e., unrelated filler).

Most studies on filling time determined fillers' effects on customers' emotional responses, service quality evaluations, and service satisfaction. Customers' emotional responses correlate to the level at which they recognize the time filling (Taylor 1994). Customers who recognize high time-filling levels exhibit reduced negative emotional responses, implying that filling wait times could distract customer attention. Customers evaluate service quality more positively when there is a filler than when there is not (Taylor 1995) and are also more satisfied (Jin et al. 2009), suggesting that service providers can stimulate positive customer responses by providing fillers during a wait.

Taylor (1995) reveals that overall performance evaluations of service encounters are higher for customers whose wait time is filled with an activity related to the service than for customers whose time is not so filled. Maister (1985) observes that servicerelated time fillers signal to customers that the "service has started" and that "we know that you are here". Pre-process waits are perceived as longer than in-process waits (Maister 1985), and Haynes (1990) argues that refocusing customers' attention away 
from their waits-ideally using methods related to the purchase experience-shortens their perceived waiting times and prevents feelings of rage.

Based on studies on waiting and fillers, we identified four relevant wait types (see Figure 1). In Type 1 (no wait), customers receive a service or enter the store immediately without waiting. Type 2 is a wait with no filler provided. In Type 3, an unrelated filler is used, and Type 4 is a wait with a related filler. In the next section, we review how customers can exhibit positive emotional and psychological responses when waiting to purchase a fashion item. We then propose our research hypotheses.

\section{Customers' psychological and emotional responses to waiting Expectation for customer competition}

Customers tend to become sensitive when perceiving crowding, a response attributed to the combined result of physical, social, and human factors (Stokols 1972). Customers expect a store to be crowded when its manager is lining up customers to ensure a smooth purchasing process and prevent problems by minimizing in-store chaos. This waiting experience leads the customers to assume that the store's products are scarce (Jun et al. 2004). The more crowded the store, the more customers expect to compete with others to purchase an item. Customers expect competition between customers even before they enter a store. When the volume of in-store products is limited, customers take urgent action such as hoarding to obtain the limited product (Byun and Sternquist 2008; 2011). Customers are more likely to expect competition when they have to wait in line to enter a store than when they do not.

Although a filler can incite a positive response to waiting, customers who wait in front of a store with an unrelated filler tend to expect less competition because unrelated fillers divert customers' attention from the shopping situation. By contrast, a related filler maximizes waiting customers' sense of competition by increasing their focus on the shopping situation and their sense of starting a purchase situation. We thus propose the hypotheses below:

Hypothesis 1. Expectations about competition will differ among wait types.

Hypothesis 1-1. People in a no-waiting situation will expect less competition than will those engaged in other wait types.

Hypothesis 1-2. People involved in a related filler will expect more competition than will those involved in other wait types.

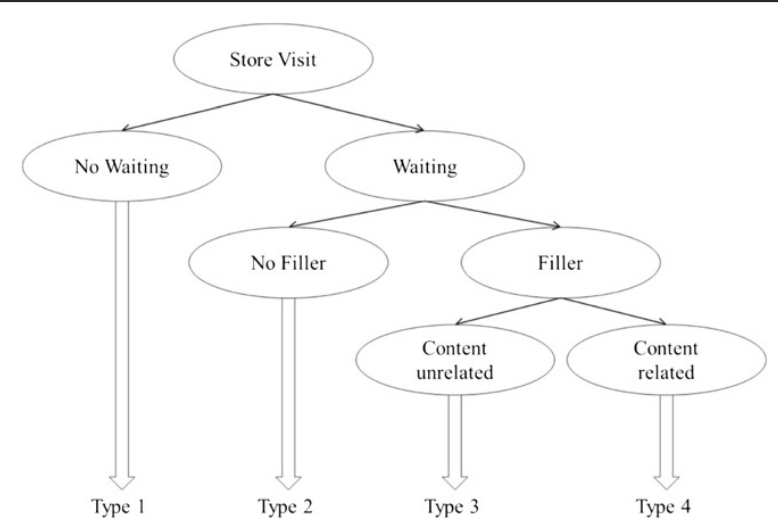

Figure 1 Categorization of wait types. 


\section{Feeling of excitement}

Customers' emotional responses are categorized as the "preceding mood" before encountering a stimulus like clothing and "experienced affection" after encountering a stimulus at the store. Studies indicate that customers shopping for fashion goods likely exhibit a positive preceding mood in anticipation of self-gratification and an exciting experience (Park 2003; Park and So 2000). Seeing a crowded store can evoke excitement in customers even before entering the store (Park 2008). In the context of purchasing a fashion item, customers are more excited when they have to wait in line than when they do not. When customers have to wait in front of the store, fillers can be provided to fill waiting time. When an unrelated filler is provided, two possible situations occur. Since an unrelated filler diverts customers' attention from the shopping situation, providing an unrelated filler can possibly decrease customers' feelings of excitement for shopping more than providing no filler at all. In contrast, providing an unrelated filler might strengthen customers' feelings of excitement because of the presence of the filler itself. For example, if a television program is too much fun or snacks are too tasty, customers' excitement can be increased. Last, since a related filler helps customers focus on the purchase, providing a related filler is expected to maximize customers' feelings of excitement. Accordingly, three hypotheses are formulated.

Hypothesis 2. Feeling of excitement will differ among wait types.

Hypothesis 2-1. People who involved in a no waiting situation will have a lower feeling of excitement as compared to other wait types.

Hypothesis 2-2. People who involved in a related filler will have a higher feeling of excitement as compared to other wait types.

\section{Purchase intention}

Customers tend to evaluate a product as being more valuable when more people are waiting in line behind them for it. In addition, the more they value the product, the more money they will spend on it (Koo and Fishbach 2010). The increasing number of people waiting behind a customer indicates greater in-store chaos, and customers' purchase intention is expected to increase. Customers also tend to attribute more value to scarce products (Jun et al. 2004) because humans unconsciously consider things that cannot be obtained easily as being more valuable (Lynn 1992). As waiting to purchase fashion goods maximizes perceived product scarcity, customers will value the product more, positively affecting their purchase intention. According to wait-type reasoning, customers are more likely to purchase a product they have waited in line for. When an unrelated filler is provided during the wait, purchase intention is expected to decrease more than when a related filler is used because the customers' attention has been diverted. When a related filler is provided during the wait, customer attention on the shopping situation increases, thereby stimulating purchase intention. We thus propose the two following hypotheses:

Hypothesis 3. Purchase intention levels will differ among the wait types.

Hypothesis 3-1. People in a no-waiting situation will have lower purchase intentions then will those involved in other wait types.

Hypothesis 3-2. People involved in a related filler will have higher purchase intentions than will those in other wait types. 


\section{Relationship between expectation of competition, feeling of excitement, and purchase intention}

It has been argued that, "when an individual's freedom to engage in a specific behavior is threatened, the threatened behavior becomes more attractive according to reactance theory" (Lessene and Notarantonio 1988, p. 34). Psychological reactance theory states that one's desire to possess a product increases when one's purchase or entry to the store is restricted because of in-store crowding or product scarcity (Brehm and Brehm 1981). According to Brehm (1989), the fundamental idea of reactance theory is that people are motivated by a threat to, or an elimination of, behavioral freedom. The social psychological principles of reactance theory were discussed in the early consumer research (Lessene and Venkatesan 1989). For example, when retailers impose limits when advertising products (e.g., one per customer), consumers are more likely to buy them (Lessene and Notarantonio 1988). Customers have a greater desire to own a product when they feel that it is scarce and that they are competing to purchase it (Brock and Brannon 1992). Chaos in a retail environment incites customer competition, and competition makes customers feel excited (Nichols 2010). Customers' purchasing behaviors vary based on their preceding moods and level of excitement (Park and So 2000). Expectations of competition are expected to affect purchase intention directly and indirectly through the mediation of excitement levels. The last hypothesis is thus the following:

\section{Hypothesis 4. Excitement level mediates the relationship between expectation of competition and purchase intention.}

\section{Method}

Instrument

The survey comprised a written scenario representing four different types of waiting to purchase a fashion item, waiting being a frequent phenomenon at luxury outlet shopping malls. The respondents were randomly assigned a scenario and provided basic information about the luxury outlet and the waiting condition (65 responses were provided for the no-wait scenario, 65 for the waiting-with-no-filler scenario, 70 for the waiting-with-unrelated-filler scenario, and 66 for the waiting-with-related-filler scenario). After reading the scenario, respondents answered questions measuring their expectations of competition, excitement level, and purchase intention. The waitingwith-related-filler scenario is provided in the Appendix. Table 1 summarizes the four waiting conditions.

The waits lasted about 15 minutes. A pretest was conducted to determine the scenarios' waiting times by asking 30 people chosen through random sampling to respond to "I could wait 5 minutes in front of a store' and "Waiting in front of a store for 5 minutes is long". We also asked for a response to the same statements concerning wait times of $10,15,20,25$, and 30 minutes. All measures were plotted on seven-point Likert-type

Table 1 Summary of the four waiting conditions

\begin{tabular}{llll}
\hline No wait & Wait with no filler & Wait with unrelated filler & Wait with related filler \\
\hline $\begin{array}{l}\text { Entering the store } \\
\text { immediately }\end{array}$ & 15-minute wait & $\begin{array}{l}\text { 15-minute wait with coffee and } \\
\text { snack provided by the store }\end{array}$ & $\begin{array}{l}\text { 15-minute wait with new item } \\
\text { catalogs and event flyers provided } \\
\text { by the store }\end{array}$ \\
\hline
\end{tabular}


scales anchored on "strongly disagree" (1) and "strongly agree" (7). The researchers sought to use wait times that carried no positive or negative preconceptions. As the results showed that participants perceived 15 minutes as being moderate $(M=4.86$, $\mathrm{M}=4.33$ for each question), this period was selected for the scenarios. Coffee and snacks were chosen as unrelated fillers and a brand catalog and event flyer as related fillers. The examination was confined to pre-process waits before entering a store to purchase a fashion product.

The researchers tested the sample's invariance among four scenarios. We found no difference in the demographic characteristics. A $\chi^{2}$ test verified that the four scenario groups were equivalent in terms of age $\left(\chi^{2}=2.446, p=.982\right)$, marital status $\left(\chi^{2}=2.906\right.$, $\mathrm{p}=.821)$, monthly income $\left(\mathrm{X}^{2}=13.089, \mathrm{p}=.786\right)$, and education level $\left(\mathrm{X}^{2}=9.603\right.$, $\mathrm{p}=.384)$. We also confirmed that the competitive expectation, excitement, and purchase intention of all groups followed the normal distribution. Therefore, we combined the scenario data to analyze each hypothesis.

The survey comprised four questions measuring the expectation of competition, three questions measuring excitement level, three questions measuring purchase intention, and one question measuring current mood using a 7-point Likert scale ranging from "never" (1) to "very much" (7). The scales were adopted from previous studies and modified to suit this research. For example, to measure customers' expectation of competition, we used items employed to measure perceived competition in Byun and Mann (2011). To measure excitement level, we employed items used in Richins (1997), and our items measuring purchase intention were drawn from Park et al. (2007) and Kim and Ko (2010). This research suggests that waiting to purchase a product can incite positive responses and thus contests the current view that waiting induces negative responses such as frustration, anger, anxiety, and dissatisfaction. Customers' current moods were also measured with a single question after they read the scenario.

The survey data were analyzed using SPSS 18.0. Before the research model analysis, descriptive statistics, reliability, and exploratory factor analysis were conducted. Hypotheses were then confirmed through ANOVA, mean comparison, and multiregression analysis.

\section{Sample}

An online survey was conducted with a panel comprising members of a professional research company that had 1.5 million online panels nationwide. All participants were Koreans living in Seoul between 19 and 59. Luxury brand outlet malls first appeared in the US and Japan; now Asian consumers are exhibiting a substantial demand for luxury goods and luxury brand outlet malls (Kim et al. 2009). South Korea is the third-largest luxury market in Asia, and its market has strategic value for global luxury fashion brands because it is widely viewed as the regional fashion leader, and many Asian travelers visit to shop for luxury items (Song 2014). Therefore, it is important to understand and predict Korean and Asian consumers' behavior at luxury brand outlet malls.

Women who were aware of and had visited a luxury fashion product outlet were selected as the respondents of this study. A total of 266 of the 280 collected surveys were used for the final analysis. The largest group of respondents was in their 20s (24.8\%), followed by those in their 30s (23.3\%). Most respondents had obtained college degrees (75.9\%), 66.5\% were married, and $60.9 \%$ had a monthly income of over 4,000 USD. 


\section{Results}

\section{Exploratory factor analysis}

Before the hypotheses were tested, customer responses to waiting were conceptualized as variables and their reliability and validity confirmed (see Table 2). In the exploratory factor analysis, factors with an eigenvalue of 1 or more were extracted with varimax rotation, and reliability of the extracted factor was analyzed. The eigenvalue of the expectation of competition was 5.168. Each question attained validity with a factor loading value of .70 or more. Level of excitement was also found to be a single factor. The total explained variance was $17.194 \%$, the eigenvalue was 1.719 , and the factor loading values for each question were over .80 , confirming validity. Finally, purchase intention was also considered a single factor with a total explained variance of $10.236 \%$, an eigenvalue of 1.024 , and factor loading values for each question measuring above .80. The Cronbach's alpha values were $.864, .928$, and .875 respectively, sufficient to confirm reliability.

\section{Research hypotheses testing}

For the mean comparison of the four groups, one-way ANOVA and Student-NewmanKeuls multiple comparison were conducted. Multi-regression analysis confirmed the causal relationship between variables and the mediating effect of excitement. The results are presented in Tables 3 and 4.

First, the mean differences of the expectation of competition by wait type were found to be significant; thus, Hypothesis 1 was supported. The Student-Newman-Keuls multiple comparison indicated that the mean of the no-wait situation was not significantly low compared to waiting with no filler and waiting with a non-related filler but that the mean of the no-wait situation was significantly high compared to the wait with related filler $\left(\mathrm{M}^{\text {Related Filler }}=4.91, \mathrm{M}^{\text {No Filler }}=4.48, \mathrm{M}^{\text {No Wait }}=4.08, \mathrm{M}^{\text {Unrelated Filler }}=3.97\right)$. The mean of waiting with a related filler was significantly high compared to the other types. Therefore, Hypothesis 1-1 was partially supported and Hypothesis 1-2 fully supported. When customers have to wait to purchase a fashion item, providing fillers related to the item or brand maximizes customers' expectation of competition as a positive response. Customers provided with fillers unrelated to fashion items tend to expect less competition than do customers provided with no fillers.

The mean differences of excitement levels by wait type were found to be significant; thus, Hypothesis 2 was supported. The mean values of related filler, no filler, no wait, and unrelated filler occur in descending order $\left(\mathrm{M}^{\text {Related Filler }}=5.03, \mathrm{M}^{\text {No Filler }}=4.52, \mathrm{M}^{\text {Unrelated Filler }}=\right.$ 4.43, $\mathrm{M}^{\text {No Wait }}=4.01$ ). The Student-Newman-Keuls multiple comparison showed that the no-wait situation yielded a lower excitement score than did the situations with no filler, unrelated filler, and related filler, supporting Hypothesis 2-1. Concerning excitement levels, customers felt most excited when provided with a related filler, a significantly different result from that for the other types as shown by a post-hoc test. Therefore, Hypothesis 2-2 was supported. Meanwhile, the significant difference between a no-wait situation and waiting with no filler demonstrated that the wait itself excited customers even though there were no fillers, confirming the positive effect of waiting. Unlike for the expectation of competition, customers with an unrelated filler felt more excited than did customers with no wait but less excited than did customers with a related filler. Customers with an unrelated filler did not feel as excited as did customers with no filler, implying that an unrelated filler alleviates the effect of waiting to induce a positive response, such as a feeling of excitement. 
Table 2 Factor analysis of scales

\begin{tabular}{|c|c|c|c|c|c|}
\hline Variable & Item & $\begin{array}{l}\text { Factor } \\
\text { loading }\end{array}$ & $\begin{array}{l}\text { Eigen } \\
\text { value }\end{array}$ & $\begin{array}{l}\text { Explained variance (\%) } \\
\text { (Cumulative Variance) }\end{array}$ & $\begin{array}{l}\text { Cronbach's } \\
\text { Alpha }\end{array}$ \\
\hline \multirow[t]{4}{*}{ Expectation of competition } & I expect to compete with other customers in line. & .865 & 5.168 & 51.677 & .864 \\
\hline & I mind the actions of other customers in line. & .853 & & & \\
\hline & I feel I will compete to purchase a specific product with other customers in line. & .784 & & $(51.677)$ & \\
\hline & I feel I must run into the store when the wait is over. & .741 & & & \\
\hline \multirow[t]{3}{*}{ Level of excitement } & I am excited with the thought of entering the store soon. & .861 & 1.719 & 17.194 & .928 \\
\hline & I am thrilled with the thought of entering the store soon. & .868 & & $(68.871)$ & \\
\hline & I feel passionate about the thought of entering the store soon. & .839 & & & \\
\hline \multirow[t]{3}{*}{ Purchase intention } & I will recommend a product in this store to others. & .869 & 1.024 & 10.236 & .875 \\
\hline & I will purchase a product in this store. & .838 & & $(79.107)$ & \\
\hline & I have the intention to purchase a product in this store. & .825 & & & \\
\hline
\end{tabular}


Table 3 Mean differences in expectation of competition, level of excitement, and purchase intention by wait type

\begin{tabular}{llll}
\hline Wait type & Expectation of competition & Level of excitement & Purchase intention \\
\hline No wait & $4.08^{\mathrm{a}}(\mathrm{AB})^{\mathrm{b}}$ & $4.01(\mathrm{~A})$ & 4.27 \\
Wait with no filler & $4.48(\mathrm{~B})$ & $4.52(\mathrm{~B})$ & 4.37 \\
Wait with unrelated filler & $3.97(\mathrm{~A})$ & $4.43(\mathrm{~B})$ & 4.25 \\
Wait with related filler & $4.91(\mathrm{C})$ & $5.03(\mathrm{C})$ & 4.41 \\
F & $8.632^{* * *}$ & $8.359^{* * *}$ & .439 \\
\hline
\end{tabular}

${ }^{* * *} \mathrm{p}<.001$.

"The average value measured on a 7-point Likert scale ranging from "never" (1) to "very much" (7).

${ }^{b}$ After the multiple comparisons of the Student-Newman-Keuls, groups found to be significant within the .05 levels were labeled with different letters.

Hypotheses 3, 3-1, and 3-2 were not supported. After the post-hoc test, no significant differences in purchase intention among wait types were found. However, regardless of wait type, survey respondents generally scored high values of more than 4.25 . These unexpected results can be attributed to the unique shopping situation in the scenario. We assume that customers who take the time to plan shopping trips to a large-scale luxury outlet located on the outskirts of a city tend to have a higher purchase intention regardless of the wait time. Another explanation is also possible. In the scenario, the premium outlet was famous and the brand was the respondents' favorite; the store was also crowded. Tse et al. (2002) argued that crowded restaurants were related to higher levels of reputation and perceived food quality. Pons et al. (2006) confirmed that a crowded hedonic consumption setting could arouse a positive evaluation from customers.

Hypothesis 4 was confirmed by the three-step mediation effect confirmation method suggested by Kenny et al. (1998). The results indicated that a feeling of excitement partially mediated the effect of the waiting customers' expectations of competition on purchase intention (see Table 4). The first step of the multiple regression for the expectation of competition on purchase intention was $14.3 \%$. At the third step of the multi-regression with feeling of excitement added, $35.1 \%$ of the variance in purchase intention was explained, a $21 \%$ increase in explanatory power. By including feeling of excitement in the regression equation, the beta coefficient of the expectation of competition decreased from .382 to .129 , implying the partial mediating effect of excitement level. Through this multi-regression analysis, both expectation of competition and excitement level were identified as important variables affecting customers' purchasing intentions. In other words, purchase intention could be increased by inducing fashion goods customers' positive responses during pre-process waits.

Table 4 Three-step regression analysis for the mediating effect of excitement

\begin{tabular}{lllllllll}
\hline Step & Dependent variable & Independent variable & $\mathbf{b}$ & $\boldsymbol{\beta}$ & $\mathbf{t}$ & $\mathbf{R}^{\mathbf{2}}$ (Modified $\mathbf{R}^{\mathbf{2}}$ ) & $\mathbf{F}$ \\
\hline 1 & Purchase Intention & Expectation of Competition & .303 & .382 & $6.715^{* * *}$ & $.146(.143)$ & $45.095^{* * *}$ \\
2 & Level of Excitement & Expectation of Competition & .475 & .483 & $8.968^{* * *}$ & $.233(.231)$ & $80.417^{* * *}$ \\
3 & Purchase Intention & Expectation of Competition & .102 & .129 & $2.278^{*}$ & $.356(.351)$ & $86.017^{* * *}$ \\
& & Level of Excitement & .423 & .524 & $9.275^{* * *}$ & & \\
\hline
\end{tabular}

$* * * p<.001,{ }^{*} p<.05$. 


\section{Discussion and conclusion}

Waiting in line to purchase products at luxury brand department stores or luxury outlet malls has recently become a common customer experience. Since many people find waiting to purchase fashion goods less common than waiting to receive service in hospitals, banks, restaurants, or airports, little research has been done on waiting in the purchasing context. This study on waiting while shopping for fashion goods categorized wait times in terms of the use of time fillers. We examined customers' psychological and emotional responses and purchase-related behaviors. We found different effects for waiting and fillers on customer's responses, expectation of competition, and excitement level. Using related fillers during the wait showed the highest positive responses, such as the expectation of competition and excitement level. The positive responses to unrelated fillers were lower than were those for related fillers. We can infer that unrelated fillers distract customers' attention from the wait or their shopping. Furthermore, excitement level was found to partially mediate the relationship between expectation of competition and purchase intention, reinforcing the importance of positive emotions in shopping situations.

Since waiting is frequent in the purchasing context, in-store customer management must extend itself outdoors. Most important for understanding customers' waits is knowing that they do not always arouse negative customer responses. Most customers consider shopping a positive experience, and this research confirms that waiting during shopping does not necessarily detract from the positive experience, as suggested in previous research (Park 2000; Koo and Fishbach 2010). We conclude that waits due to crowding reinforce customers' perceptions of product value and competition, consequently stimulating their positive emotional responses to the shopping situation. When limited product availability is hinted, customers expect competition with other customers, become excited, and demonstrate greater purchase intention. This result is consistent with the finding that the more customers recognize perishability and scarcity, the more they conduct in-store hoarding (Byun and Sternquist 2008; 2011).

Since customers' psychological and emotional responses while waiting directly influence their purchases after entering the store, it is important to provide a proper waiting environment. When unrelated fillers were provided, customers' attention was diverted, which may reduce not only negative responses but also positive responses such as expectation of competition and excitement in shopping. It is ideal to reinforce the positive effect of waiting for both customers and store managers. Limiting the number of in-store customers and forming a decent queue outside the store benefits both.

Effectively managing related fillers during a wait is key for store management and customer satisfaction. Technological advances are increasing the sophistication of related fillers. Recent studies indicate that promotion methods such as real-time information on special events and sales using mobile devices are more effective than are traditional marketing media (Shankar and Balasubramanian 2009; Bolton and SaxenaIyer 2009). Such personalized and free marketing is more effective when customers are provided with related fillers with QR codes or the brand's mobile applications during their wait. Consumers can then enjoy better information, while marketers are provided with cost-effective marketing opportunities.

The key contribution of this research is its focus on waiting in the context of purchasing fashion goods, which differs from previous research conducted in the service context. In addition, this research confirms the positive impact of waiting by providing empirical 
evidence concerning shopping for fashion goods. Finally, this research offers an analysis of the role of unrelated fillers during wait times. Further investigation is needed of how other variables, such as store image and service satisfaction, impact waiting situations for other product categories. Moreover, as this study was limited to a specific store type (i.e., outlet mall), wait type (i.e., pre-process wait), wait time (i.e., 15 minutes), and temporal condition (i.e., the weekend), future studies should address broader contexts beyond this limitation. Future research could also examine the effect of various types of related fillers, such as those using digital technology that enables mutual interaction.

\section{Appendix}

\section{Full text of scenario 4 with related filler}

The nation's famous premium outlet $\mathrm{A}$, a new shopping center with a variety of brand stores, including luxury brand stores, opened in 2010 on the outskirts of XXX city. This outlet mall is a complex cultural space with a wide variety of fashion items as well as restaurants, cafes, parks, and amusement facilities. Customers come from every corner of the country, and they cannot avoid waiting in long lines, especially on the weekends.

You are visiting the nation's famous luxury outlet A for the weekend to purchase a new outfit and purse for the approaching season. You proceed to your favorite brand B store to take a look at the brand's new items.

When you arrive at the store, you notice that it is very crowded, full of other customers. You have no choice but to wait in a long line to enter the store. While waiting, a store manager approaches you and hands you the brand's new item catalogs and event flyers. You look at every page of the catalogs and flyers closely. You spend your waiting time checking off the items you like and want to see inside the store.

Finally, the time has passed, and it is your turn to enter the store. When you check the time on your cellphone, 15 minutes have passed since you began waiting in line.

Competing interests

The authors declare that they have no competing interests.

\section{Acknowledgements}

This work was supported by BK21 Plus project of the National Research Foundation of Korea Grant funded by the Korean Government.

Received: 20 August 2014 Accepted: 3 November 2014

Published online: 29 November 2014

\section{References}

Antonides, G, Verhoef, PC, \& Van Aalst, M. (2002). Consumer perception and evaluation of waiting time: a field experiment. Journal of Consumer Psychology, 12, 193-202.

Arthurs, D. (2012). Sold out again? H\&M strike gold once more with Marni collection shoppers say is the 'essence of the brand'. Mail Online, Retrieved June 5, 2014 from http://www.dailymail.co.uk/femail/article-2111995/H-M-Marnicollection-H-M-strike-gold-designer-collaboration.html\#ixzz33kUKBBZr.

Bolton, R, \& Saxena-lyer, S. (2009). Interactive services: a framework, synthesis and research directions. Journal of Interactive Marketing, 23, 91-104.

Brehm, JW. (1989). Psychological reactance-theory and applications. Advances in consumer research, 16, $72-75$.

Brehm, SS, \& Brehm, JW. (1981). Psychological Reactance: A Theory of Freedom and Control. New York: Academic Press.

Brock, TC, \& Brannon, LA. (1992). Liberalization of commodity theory. Basic and Applied Social Psychology, 13, 135-144.

Byun, S-E, \& Mann, M. (2011). The influence of others: the impact of perceived human crowding on perceived competition, emotions, and hedonic shopping value. Clothing and Textiles Research Journal, 29, 284-297.

Byun, S-E, \& Sternquist, B. (2008). The antecedents of in-store hoarding: measurement and application in the fast fashion retail environment. The International Review of Retail, Distribution and Consumer Research, 18, 133-147.

Byun, S-E, \& Sternquist, B. (2011). Fast fashion and in-store hoarding: the drivers, moderator, and consequences. Clothing and Textiles Research Journal, 29, 187-201.

Chebat, J-C, Filiatrault, P, Gelinas-Chebat, C, \& Vaninsky, A. (1995). Impact of waiting attribution and consumer's mood on perceived quality. Journal of Business Research, 34, 191-196. 
Cho, JE, \& Kim, SW. (2007). Service waiting: how wait times affect service evaluations. Korean Management Review, 36(7), $1785-1810$.

Davis, MM, \& Heineke, J. (1998). How disconfirmation, perception and actual waiting times impact customer satisfaction. International Journal of Service industry Management, 9, 64-73.

Davis, MM, \& Vollmann, TE. (1990). A framework for relating waiting time and customer satisfaction in a service operation. Journal of Services Marketing, 4, 61-69.

Dube-Rioux, L, Schmitt, BH, \& Leclerc, F. (1989). Consumers' reactions to waiting: when delays affect the perception of service quality. Advances in consumer research, 16, 59-63.

Gilliland, A, Hofeld, J, \& Eckstrand, G. (1946). Studies in time perception. Psychological Bulletin, 43, 162-176.

Haynes, PJ. (1990). Hating to wait: managing the final service encounter. Journal of Services Marketing, 4(4), 20-26.

Houston, MB, Bettencourt, LA, \& Wenger, S. (1998). The relationship between waiting in a service queue and evaluations of service quality: a field theory perspective. Psychology \& Marketing, 15, 735-753.

Hui, MK, \& Tse, DK. (1996). What to tell consumers in waits of different lengths: an integrative model of service evaluation. The Journal of Marketing, 60, 81-90.

Jin, YH, Park, MY, Kim, MK, \& Kim, SS. (2009). The effects of waiting service factors of food service companies on customer satisfaction. Korea Journal of Tourism and Hospitality, 23, 183-198.

Jun, SY, Huh, JH, \& Kim, HD. (2004). The effects of the type of scarcity message on consumer purchase intention. Journal of Korean Marketing Association, 19, 71-89.

Katz, KL, Larson, BM, \& Larson, RC. (1991). Prescription for the waiting-in-line blues: entertain, enlighten, and engage. Sloan Management Review, 32, 44-53.

Kenny, DA, Kashy, DA, \& Bolger, N. (1998). Data analysis in social psychology. The handbook of social psychology, 1(4), 233-265.

Kim, HW. (2012). H\&M, Marni collaboration, Customers all night up unusual scene. Seoul Economy, Retrieved June 5, 2014, from http://economy.hankooki.com/ArticleView/ArticleView.php?url=industry/201203/e20120308184411120210.htm\&ver=v002.

Kim, AJY, \& Ko, EJ. (2010). The impact of design characteristics on brand attitude and purchase intention. Journal of the Korean Society of Clothing and Textiles, 34, 252-265.

Kim, G, Kim, A, \& Sohn, SY. (2009). Conjoint analysis for luxury brand outlet malls in Korea with consideration of customer lifetime value. Expert Systems with Applications, 36, 922-932.

Koo, M, \& Fishbach, A. (2010). Climbing the goal ladder: how upcoming actions increase level of aspiration. Journal of personality and social psychology, 99, 1-13.

Leclerc, F, Schmitt, BH, \& Dube, L. (1995). Waiting time and decision making: is time like money? Journal of Consumer Research, 22, 110-119.

Lee, J. (2012). 10 million dollars sales per store, sold out in 2 hours of promotion. Chosun Biz, Retrieved April 5, 2012, from http://biz.chosun.com/site/data/html_dir/2012/03/09/2012030900926.html.

Lessne, GJ, \& Notarantonio, EM. (1988). The effect of limits in retail advertisements: A reactance theory perspective. Psychology \& Marketing, 5(1), 33-44.

Lessne, G, \& Venkatesan, M. (1989). Reactance theory in consumer research: the past, present and future. Advances in Consumer Research, 16(1), 76-78.

Lynn, M. (1991). Scarcity effects on value: a quantitative review of the commodity theory literature. Psychology \& Marketing, 8, 43-57.

Lynn, M. (1992). The psychology of unavailability: explaining scarcity and cost effects on value. Basic and Applied Social Psychology, 13, 3-7.

Maister, DH. (1985). The Psychology of Waiting Lines (The Service Encounter, John Czepiel, Michael Solomon, and Carol Suprenant, eds, pp. 113-123). Lexington, MA: Lexington Books.

Nichols, BMS. (2010). Exploring and Explaining Consumer Competition: A Mixed-Methods Approach to Understanding the Phenomenon (Unpublished PhD thesis). Knoxville: University of Tennessee.

Park, YS. (2000). The effect of waiting time on service evaluation. Journal of Korean Marketing Association, 15, 1-25.

Park, K. (2003). The effects of retail crowding on consumer emotions and shopping behaviors. Journal of the Korean Society of Clothing and Textiles, 27, 261-269.

Park, S-Y. (2008). The relation among store crowding, shopping emotions and shopping value. Journal of Distribution Science, 6, 61-79.

Park, EJ, \& So, GS. (2000). Effects of affective factors on apparel buying behaviors. Journal of the Korean Society of Clothing and Textiles, 24, 361-372.

Park, H-H, Jeon, JO, \& Kwak, W. (2007). The influence of perceived quality and VMD fitness of fashion brand on brand attitude and purchase intention. Journal of Marketing Management Research, 12, 55-70.

Parker, RS, Pettijohn, C, Pettijohn, L, \& Kent, J. (2003). An analysis of customer perceptions: factory outlet malls versus traditional department stores. Marketing Management Journal, 13, 29-44.

Phau, I, \& Prendergast, G. (2000). Consuming luxury brands: the relevance of the 'rarity principle'. The Journal of Brand Management, 8(2), 122-138.

Pons, F, Laroche, M, \& Mourali, M. (2006). Consumer reactions to crowded retail settings: Cross-cultural differences between North America and the Middle East. Psychology \& Marketing, 23(7), 555-572.

Richins, ML. (1997). Measuring emotions in the consumption experience. Journal of consumer research, 24, $127-146$.

Shankar, V, \& Balasubramanian, S. (2009). Mobile marketing: a synthesis and prognosis. Journal of Interactive Marketing, 23, 118-129.

Shergill, GS, \& Chen, Y. (2008). Customer perceptions of factory outlet stores versus traditional department stores. Marketing Intelligence \& Planning, 26, 77-96

Song, JA. (2014). Luxury Brands Battle to Stay in Fashion in South. Financial Times: Korea.

Stokols, D. (1972). On the distinction between density and crowding: some implications for future research. Psychological review, 79, 275-277.

Tansik, DA, \& Routhieaux, R. (1999). Customer stress-relaxation: the impact of music in a hospital waiting room. International Journal of Service Industry Management, 10, 68-81. 
Taylor, S. (1994). Waiting for service: the relationship between delays and evaluations of service. The Journal of Marketing, 58, 56-69.

Taylor, S. (1995). The effects of filled waiting time and service provider control over the delay on evaluations of service. Journal of the Academy of Marketing Science, 23, 38-48.

Tse, ACB, Sin, L, \& Yim, FH. (2002). How a crowded restaurant affects consumers' attribution behavior. International Journal of Hospitality Management, 21(4), 449-454.

Yoo, C-J, \& Kim, S-H. (1994). Exploratory research about shopping behavior through an ethnographic approach: extended concept, diversity of emotion, diversity of motive. Journal of Consumer Studies, 5, 45-62.

Yoon, S-W, \& Kim, S-B. (2003). The effects of physical environment, perceived justice and perceived waiting-time on repurchase intention. Journal of Global Academy of Marketing Science, 12, 135-153.

doi:10.1186/s40691-014-0021-6

Cite this article as: Park et al:: Waiting in line at a fashion store: psychological and emotional responses.

Fashion and Textiles 2014 1:21.

Submit your manuscript to a SpringerOpen ${ }^{\circ}$ journal and benefit from:

- Convenient online submission

- Rigorous peer review

- Immediate publication on acceptance

- Open access: articles freely available online

- High visibility within the field

- Retaining the copyright to your article

Submit your next manuscript at $>$ springeropen.com 